\title{
An Exploration on the Teaching Reform of Bilingual Educational Basic Medical Courses for the Biomedical Engineering Majors of Universities of Science and Technology
}

\author{
Shuo Yang ${ }^{1}$,Lei Zhang ${ }^{2}$ \\ 1 Jilin Business and Technology College, Changchun, 130507, China \\ ${ }^{2}$ Changchun Equipment and Technology Research Institute,Changchun,130012,China \\ ayangyu1983@sina.com
}

Key words: Basic Medicine, Biomedical Engineering, Teaching Reform

\begin{abstract}
Basic medical courses develop relatively slow in the biomedical engineering major of universities of science and technology. This is related with the cultivation objects for students in the universities of science and technology. Most of such schools cultivate the students' abilities of operation and engineering practice. Then, how to take the advantages of the students of sciences and engineering in the basic medicine teaching in biomedical engineering major has become a problem faced by universities of science and technology. This essay has explored deeply the teaching reform of basic medical courses for the biomedical engineering majors of universities of science and technology.
\end{abstract}

\section{Introduction}

Relying on engineering science, the biomedical engineering major is an interdiscipline subject with the basic medicine as the platform. The main role of the subject is solving the problems occurred in basic medicine by utilizing the principles and technology of engineering science. Thus, the biomedical engineering major is vital to the modern medicine.But most of biomedical engineering majors in the current universities of science and technology were opened in the recent 20 years. The teaching of the courses related to basic medicine has not formed a systematic teaching system. The teachers' level and experimental conditions have a distinctive gap with those of relatively professional medical schools. The practice base is usually far away from school and it is difficult for the students to have real opportunities to participate in hand on the work related with the basic medicine. In terms of curriculum, the courses of engineering science in the university of science and technology always occupy the class hours of basic medical courses, making them have huge contents within limited lessons. Therefore, how to make the students of biomedical engineering major understand and master the related knowledge of basic medical courses and make the basic medical courses and the other courses of biomedical engineering major form an integrated system has become a problem for the educators in the universities of science and technology. Against the current problems faced by universities of science and technology, this essay has explored the teaching reform of basic medical courses in the biomedical engineering major of universities of science and technology.

\section{Integration of the Characteristics of School and Basic Medical Courses}

University of science and technology usually has its own advantages in engineering courses, including characteristic photoelectricity or mechanical automation and etc. This requires that the characteristics must be combined when setting the subjects of cultivating the biomedical engineering major of such universities. A case in point is Chasngchun University of Science and Technology founded by the academician,Wang Daheng. Its characteristic major is photoelectricity. The University therefore takes it as the breakthrough point when planning the whole curriculum of biomedical engineering major. And the X-ray, which is closely related with basic medicine, is chosen as the focused training direction. The students can thus fully understand and grasp the optical properties of X-ray like wave-particle duality. On such a basis, the students will learn knowledge related to photoelectric medical instruments (such as CT, spiral CT, nuclear magnetic resonance) in combination with the basic medical knowledge of anatomy, engineering physiology and clinical medicine. In this way, the concept of photobiology and the principles of instruments and equipment are combined, making it easier for students to understand and study ${ }^{[1-4]}$. 


\section{Integration and rewriting of basic medical curriculum courses}

Currently, the textbooks of the biomedical engineering major of universities of science and technology are those adopted by medical colleges. But such textbooks are written for the students of five-year medical specialty and the universities of science and technology are four-year. In addition, the textbooks of medical colleges is detailed and deep due to the sufficient class hours. Whereas, it is laborious for the students of the universities of science and technology to lean the text books of medical colleges due to the lacking of the basis for basic medicine and the short class hours allocated for the basic medical courses for biometical engineering major ${ }^{[5]}$. Thus, it is not appropriate to let the the students of biometical engineering major of the universities of science and technology study the text books of medical colleges. However, there is no organization has written a series of basic medical textbooks suitable to the teaching of universities of science and technology. This requires the universities of science and technology to organize teachers, on the basis of its own characteristics, to write some text books for basic medicine suitable to itself.

Here, we take Changchun University of Science and Technology as an example. It takes the its characteristic photoelectricity as the cultivating target and the development direction of domestic and overseas biometical medical engineering majors as the guidance. It has organized the teachers, together with the famous experts in the first-class hospital at grade three in Changchun city and the medical schools, to rewrite the books related to the basic medical courses. Some courses are integrated as required by the courses related to basic medicine of the universities of science and technology. For example, it has organized the writing of the textbook of Physiology, with the contents of the optical characteristics of cornea in fundus added, highlighting the characteristic photoelectricity of the school. The clinical medicine and engineering technology are integrated organically and the learning of one knowledge point can thus integrate the contents of some textbooks. In this way, the key points of teaching can be highlighted with some related contents being extended and the divergent thinking ability of students can be promoted. The contents of teaching can really be thoughtful, pioneering, scientific and practical.

\section{Combination of Teaching Reform and Upgraded Teaching Methods}

In theoretical thinking, the teaching mode in which the teachers of the colleges play a leading role is changed. Teaching methods like multi-media are utilized to enrich the contents of lessons and to expand the thinking of students. The discussing-type teaching mode in which the teachers and the students are on an equal footing are set to arouse the interest of students. In combination with the characteristics of biomedical engineering major, the clinical medicine is integrated into the teaching of basic medicine. In the lecturing of theoretical knowledge, the examples of clinical medicine are combined as the basis of setting problems to strengthen the students' comprehension of the knowledge points, improving the teaching quality. Changchun University of Science and Technology is also an example in this regard. When the knowledge of hearts is taught, the shape and functions are described in details. At the same time, the medical practices are combined by means of demonstrating the heart-related equipment like electrocardiographic monitoring device, inviting the students to operate on the spot and analyzing the experimental data obtained from the experimental equipment together. Then the data will be used to compare the classic radiographic images and ultrasound images of the textbooks to analyze the changes result from heart diseases. And the students' memorization of knowledge points are enhanced by discussion in class. This method has not only aroused the enthusiasm of the students in learning but also established a new communication mode between teachers and students.

In experiment teaching, on the basis of the students have grasped the basic operation of relevant devices and the experiments specified in the teaching program are completed, the students are encouraged to put forward their own ideas and put them into practice so as to cultivate their innovative thinking patterns. Here is also an example of Changchun University of Science and Technology. In the anatomy experiment, teacher allows the students to choose their own topics, design the operational scheme by themselves and summarize it with the assistance of the teacher when the experiment is completed. This has not only enabled the students to know the basic 
knowledge of basic medical experiment and how to use devices but also cultivated their independent abilities to think about the problems and solve the problems.

In practical teaching, the scientific research projects, practice base and classroom teaching are closely connected. Take Changchun University of Science and Technology as an example. It has formed strategic allies with Jilin Qianwei Hospital, Changchun Biological Products Research Institute, Dirui Medical and other units and taken them as its teaching practical bases and second classrooms in which students can fully understand the principles and service concoctions of various kinds of cutting-edge devices. At the same time, utilizing the advantage of the theoretical innovation, colleges have conducted cooperation with practice bases in various kinds of scientific research projects. In this way, students have opportunities to know the development and demand of the biomedical engineering field. Guided by teachers, they can utilize their own theoretical knowledge to solve the realistic difficulties of related enterprises as a way to promote the further development of the biomedical engineering field.

\section{Integration of Basic Medical Courses}

According to the cultivation target of biomedical engineering major, the entire curriculum planning, teaching resources and environment, closely combining the characteristic photoelectricity of universities of science and technology, we have chosen the basic medical courses closely related with the professional cultivation, including systemic anatomy, human physiology, basic pathology, introduction to clinical medicine and biochemistry. All these courses are widely and closely connected. In the integration of courses, on the basis of anatomy, human physiology and basic pathology are integrated as physiopathology, mainly lecturing the knowledge about physiologic pathology related with the professional courses and supplemented with biological and chemical knowledge. The introduction to clinical medicine and the clinical medical engineering technology are combined as introduction to the clinical medical engineering, mainly teaching the medical instruments, the evolution of clinical mode and the application of medical apparatus and equipment in diagnosing of diseases. In this way, the six courses are integrated into three, that is, systemic analogy, physiopathology, introduction to clinical medical engineering supplemented by the experiments of analogy and physiopathology.The teaching from macro to micro can enhance the students' memorization. The teaching from morphology can help the students better the understanding of physiological function. The teaching from the norm to abnormality can enhance comparison of the two. The teaching from medicine to the principles and technology of engineering is conductive to the combination of medicine and engineering and cultivation of the students' consciousness of innovation so as to improve the teaching efficiency.

\section{Conclusion}

In teaching of the biomedical engineering major, Universities of Science and Technology must combine their own characteristic majors and change the previous cramming teaching methods. They should reasonably compile books and upgrade the teaching ways, methods and means by taking engineering science as the breakthrough point and integrating methods like internship and practice so as to improve the whole learning level of the students of biomedical engineering major and let them lay a solid foundation for work related to medical engineering.

\section{References}

[1]Luo Shifang, Sun Shanquan, A Preliminary Study on the Method of Teaching Anthropotomy of biomedical Medical Engineering Major,J. Journal of Shanxi Medical University (Preclinical Medical Education Edition).7(2005)240 -241.

[2]Deng Ling, Jiang Fengyan, Jia Bing, Exploration and Analysis on the Teaching Efficiency and Influencing Factors of the Integrated Curriculum of Medical Schools,J. Heilongjiang Education.01(2014)69-71.

[3]Han Ying, ZhouWenming, A Study on the Teaching Reform of the Engineering Specialty Courses of Ordinary Colleges and Universities,J.Journal of Jilin Business and Technology. 
06(2010)90-92.

[4]Ding Xiaodong, Chai Ying, Wang Li, An Exploration on the Teaching Reform of Medical Imaging Courses,J.Medical Education. 17(2010)105-106.

[5]Fan Xue mei, Conception of Colleges' Experiment Teaching Reform,J. Journal of Jilin Business and Technology. 05(2009)109-111. 